\title{
Giant left atrium
}

\begin{abstract}
We present a case of a patient with a giant left atrium $\left(428 \mathrm{ml} / \mathrm{m}^{2}\right)$ subjected to mitral valvuloplasty 6 years ago, who developed atrial fibrillation requiring anticoagulation with new mitral stenosis. Present new onset of recurrent upper gastrointestinal hemorrhage. Proposed replacement mitral valve added to the reduction of left atrial volume, closure of the appendage and isolation of pulmonary veins with the aim of reducing the incidence of embolic events and being able to do without anticoagulation.
\end{abstract}

Keywords: rheumatic fever, mega auricul, auricular surgery
Volume 3 Issue I - 2018

\section{Cristian M Toldo,' Sebastian E Puga,' PedroV Kairuz, ${ }^{2}$ Raul A Barreto ${ }^{2}$ \\ 'Servicio Ecocardiografia Medicina Ambulatoria Salta, Argentina ${ }^{2}$ Servicio de Cardiologia Clinica Medicina Ambulatoria Salta, Argentina}

Correspondence: Cristian Maximiliano Toldo, Servicio Ecocardiografia Medicina Ambulatoria Salta, Argentina, Email cristian_toldo@hotmail.com

\section{Clinical case}

Patient of 75 years, height $165 \mathrm{~cm}$ and weight $72 \mathrm{~kg}$, with a history of mitral valve disease secondary to Rheumatic Fever. Percutaneous valvuloplasty was performed with balloon (Tecnica de Inoue) 6 years ago. Found in permanent atrial fibrillation(AF), NYHA functional class II, medicated with acenocoumarol, enalapril $10 \mathrm{mg} 2$ times/day, carvedilol $6.25 \mathrm{mg} 2$ times/day, spironolactone $25 \mathrm{mg}$ /day, furosemide $20 \mathrm{mg} /$ day and rosuvastatin $20 \mathrm{mg}$ /day. A Doppler echocardiogram is requested for dyspnea. It highlights the great biatrial dilatation to left predominance with moderate to severe mitral regurgitation, thickened mitral valve with characteristic stiffness (anterior valve in hockey stick), mitral stenosis moderated to severe by hemipresion time (THP) with an average of 10 beats (per to be found in atrial fibrillation rhythm) and systolic pressure in the pulmonary artery of $47 \mathrm{mmHg}$. Left ventricular systolic function preserved. The left atrium measures $10.7 \mathrm{~cm}$ in the anterior-posterior direction, an area in 4 chambers of $109 \mathrm{~cm}$ and an area in 2 chambers of $102 \mathrm{~cm}^{2}$, obtaining a volume by the biplane method of $778 \mathrm{ml}\left(428 \mathrm{ml} / \mathrm{m}^{2}\right)$, remarking that currently the normal area by echocardiography is less than $34 \mathrm{ml} / \mathrm{m}^{2} .{ }^{1} \mathrm{He}$ presented with upper gastrointestinal bleeding with third episode of significant bleeding in 2 months that required blood transfusion due to gastric and duodenal ulceration. Mitral valve replacement is proposed with biological prosthesis, reduction of atrial volume, closure of left atrial appendage and isolation of pulmonary veins (Figure 1-3).

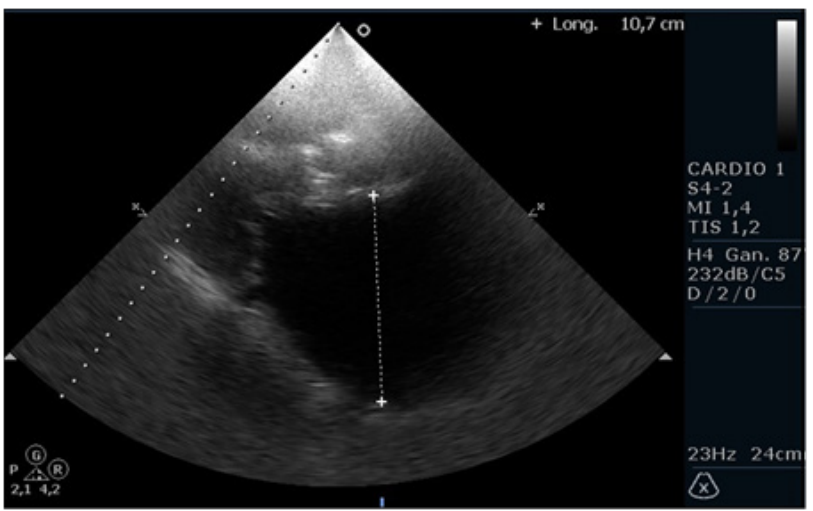

Figure I plane echocardiographic paraesternal long axis observing thickening and restriction of opening of the mitral valve and anteroposterior diameter of the left atrium increased $(10.7 \mathrm{~cm})$

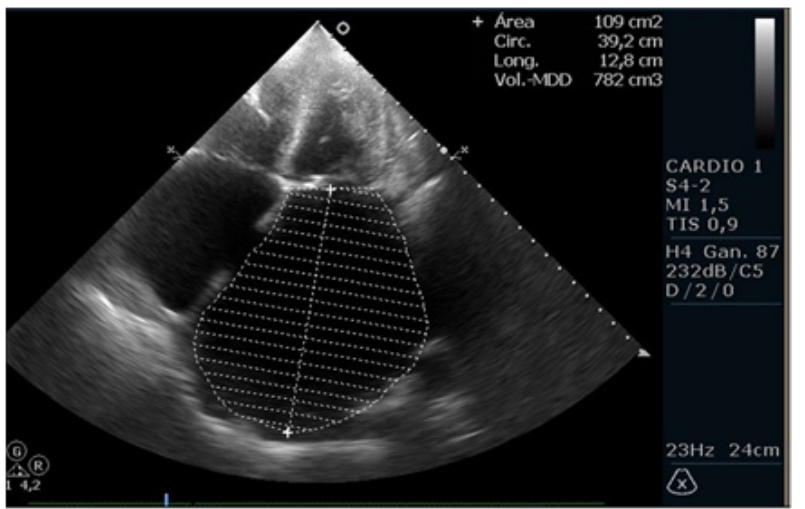

Figure 2 Apical echocardiographic view of four cameras with left atrial area measurement widely increased $\left(109 \mathrm{~cm}^{2}\right)$ and inferosuperior distance of 12.8 $\mathrm{cm}$

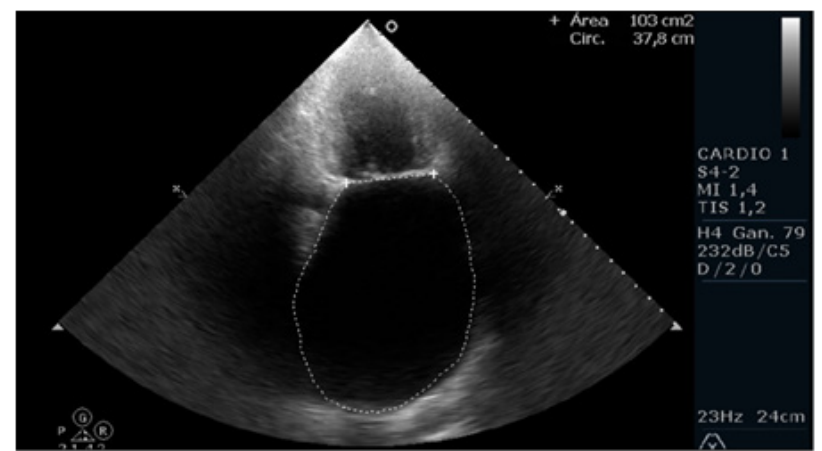

Figure 3 Apical echocardiographic view of two cameras with left atrial area measurement widely increased $(103 \mathrm{~cm} 2)$ and inferosuperior distance of 12.6 $\mathrm{cm}$. Obtaining a volume of left atrium by biplanar method of $778 \mathrm{ml}$

\section{Discussion}

It is known as giant left atrium or left mega-atrium when the anteroposterior diameter exceeds $65 \mathrm{~mm}$ for some authors ${ }^{2}$ while there are works that consider a diameter greater than $80 \mathrm{~mm}$, but there is no evidence even today in the literature of a definition of megaauricula by volume indexed to body surface. Among the causes of mega-auricula are rheumatic valvulopathy (mainly stenosis), mitral valve prolapse 
and, to a lesser extent, ventricular, systolic or diastolic dysfunction, even without significant mitral dysfunction. ${ }^{3}$

The relationship between atrial size and arrhythmias, especially atrial fibrillation, is known. In the work of Homer Ross, although with lower atrial volumes than our case, the surgical reduction of atrial size was associated with a greater reversion of AF to sinus rhythm. ${ }^{4}$ Garcia Villarreal et al. ${ }^{5}$ using the modified Sankar technique they present data with high probabilities of reversion to sinus rhythm with very large atria. $^{5}$

Currently, the indications for surgical reduction of atrial volume are the presence of compressive symptoms and/or significant mitral valvulopathy with or without atrial fibrillation. ${ }^{6}$ To which one could add the impossibility of using anticoagulation in patients who had already used it, knowing that mortality can reach up to $20 \%$ in patients undergoing valve replacement plus volume reduction in the left atrium.

In our case, a patient with indication for valvular replacement due to mitral stenosis, atrial fibrillation and recurrent upper gastrointestinal bleeding, we believe that the most cost-effective alternative is valve replacement with biological prosthesis and try to reduce atrial volume, close the left atrial appendage and treat get rhythm sinsual to avoid the use of anticoagulants.

\section{Acknowledgements}

None.

\section{Conflict of interest}

The author declares has no conflict of interest.

\section{References}

1. Lang RM, Badano LP, Mor AV, et al. Recommendations for cardiac chambers quantification by echocardiography in adults: an update fron de american society of echocardiography and the european associations of cardiovascular imaging. $J$ Am Soc Echocardiograp. 2015;28(1):139.

2. Kawazoe K, Beppu S, Takahara Y, et al. Surgical treatment of giant left atrium combined with mitral valvular disease. Plication procedure for reduction of compression to the left ventricle, bronchus and pulmonary parenchyma. J Thorac Cardiovasc Surg. 1983;85(6):885-892.

3. Kim H, Park YA, Choi SM, et al. Associates and prognosis of giant left atrium; Single center experience. $J$ Cardiovasc Ultrasound. 2017;25(3):84-90.

4. Fernando HS, Felipe AF, José AMA, et al. Auriculectomía izquierda en el tratamiento de la fibrilación muscular. Rev Esp Cardiol. 2001;54(6):703708

5. García VOA, Amadeu BG, Roberto G, et al. Reducción auricular izquierda para la fibrilación auricular crónica. Rev Esp Cardiol. 2002;55(5):499-504.

6. Apostolakis E, Shuhaiber JH. The surgical management of giant left atrium. Eur J Cardiothorac Surg. 2008;33(2):182-190. 